STUDIA HUMANITATIS JOURNAL, 202I, I (I), pp. I27-I53

ISSN: 2792-3967

D0l: https://doi.org//0.5370l/shj.vlil.15

\title{
DEFINICIÓN LEXICOGRÁFICA Y DISCURSIVO-TEXTUAL DE TELÉFONO MÓVIL A PARTIR DE UN BLOG ${ }^{12}$
}

\author{
LEXICOGRAPHICAL AND DISCURSIVE-TEXTUAL DEFINITION OF MOBILE PHONE FROM A BLOG
}

\author{
M. ${ }^{a}$ Azucena Penas lbáñez \\ Universidad Autónoma de Madrid, España \\ ORCID: 0000-0002-908I-757X \\ azucena.penas@uam.es \\ Milagros Alonso Perdiguero \\ Universidad Autónoma de Madrid, España \\ ORCID: 0000-0003-3548-4II6 \\ m.alonso.p@hotmail.es

\begin{abstract}
Resumen | La investigación se ocupa del análisis de las definiciones del item léxico teléfono móvil aportadas por alumnos a partir de un blog. Los datos obtenidos se extraen de muestras tomadas de una práctica realizada en clase durante un periodo de tiempo de un mes. Se procede a hacer el estudio de un modo inductivo: $1 .{ }^{\circ}$ ) se parte de la información contextual que ofrece la muestra del blog; $2 .^{\circ}$ ) se analiza la información lexicográfica que presentan las definiciones de dicho ítem léxico en las fuentes consultadas, tanto diccionarios escolares, que son los manejados mayoritariamente en estos niveles, como diccionarios generales con los que se contrasta, y 3.9) se finaliza con las definiciones aportadas por los alumnos, con desglose de los semas que contienen. Una vez analizada toda la información de los semas, se concluye que, en cuanto a la información lexicográfica, la hiperonimia y la metonimia son los mecanismos semánticos prevalentes en los dos tipos de diccionarios, que son, por otra parte, los que también utilizan los informantes en sus propias definiciones, las cuales, desde un punto de vista discursivo-textual, se ven favorecidas por un gran número de inferencias, presuposiciones y sobrentendidos. Se acompañan los datos de gráficos ilustrativos referentes a la información textual, la información lexicográfica y los semas del item léxico estudiado.
\end{abstract}

Palabras clave: Definición, Sema, Ítem léxico, Diccionario, Cibertexto.

\section{Abstract | The research deals with the analysis of the definitions of the mobile phone lexical item provided by students} from a blog. The data obtained are extracted from samples taken from a practice done in class during a period of time of one month. The study is carried out in an inductive way: Ist) we start from the contextual information offered by the blog sample, 2nd) we analyze the lexicographic information presented by the definitions of said lexical item in the consulted sources, both school dictionaries, which are mainly handled at these levels, such as general dictionaries with which it is contrasted and 3rd) it ends with the definitions provided by the students, with a breakdown of the semes they contain. Once all the information on the semes has been analyzed, it is concluded that, in terms of lexicographic information, hyperonymy and metonymy are the prevalent semantic mechanisms in the two types of dictionaries, which are, on the other hand, those also used by informants in their own definitions, which from a discursive-textual point of view are favored by a large number of inferences, presuppositions and

\footnotetext{
${ }^{1}$ Recibido/Received: 26/04/202I

Aceptado/Accepted: 07/06/2021

${ }^{2}$ El presente estudio se ha realizado dentro del Grupo de Investigación de la UAM Semántica y Léxico (SEMyLÉX), del que es coordinadora M. ${ }^{a}$ A. Penas lbáñez.
} 
Definición lexicográfica y discurso-textual de teléfono móvil

a partir de un blog

understandings. The data of illustrative graphics referring to the textual information, the lexicographic information and the semes of the studied lexical item are attached.

Keywords: Definition, Sema, Lexical item, Dictionary, Cybertext.

\section{| Introducción |}

Este estudio constituye la continuación de una investigación realizada a lo largo de los cursos académicos 2013-14 y 2014-15, a la que hacemos referencia en diversas investigaciones: el capítulo 8, "Estudio de caso: la comprensión textual del ciberléxico informático en usuarios de la primera generación digital o generación posmilennial", del libro El cibertexto y el ciberlenguaje, de la editorial Síntesis en 2018; el capítulo "Los semas en la definición del léxico informático. Información semántica y lexicográfica: el término nube", incluido en el Vol. Il Investigaciones actuales en Lingüística. Semántica, Lexicología y Morfología, de la Universidad de Alcalá en 2017 y, por último, el capítulo 34 "Generación millennial y comprensión lectora de ítems informáticos en blogs", dentro de Aula Virtual: contenidos y elementos, de Ediciones Universitarias McGraw-Hill en 2016.

Se trata, en esta ocasión para el término teléfono móvil, de una aplicación a la comprensión textual del ciberléxico informático mediante muestras definicionales en informantes de Educación Primaria y Secundaria, usuarios muy familiarizados con las nuevas tecnologías, integrantes de la primera generación eminentemente digital o generación millennial (Penas lbáñez, 2015b).

El corpus con el que se ha elaborado el presente estudio procede de muestras realizadas en las aulas de Educación Primaria (EP) y del primer ciclo de Educación Secundaria Obligatoria (ESO) ${ }^{3}$, a partir de un texto de blog. A los alumnos se les hizo reproducir dicho texto leído por el profesor y a continuación se les señaló el ítem teléfono móvil que debían definir, sin ninguna pauta sobre la forma de ejecutar la tarea encomendada, con vistas a observar, de forma espontánea, la competencia léxica de esta franja de alumnado en dicha temática, puesto que los informantes de las muestras escogidas no tuvieron acceso al uso de ninguno de los diccionarios con los que se ha trabajado en la investigación, según se precisará más adelante.

Los informantes contaron con el apoyo del contexto de la palabra o expresión que ha de ser definida y que, en ocasiones, les ayudó a deducir un significado aproximado, si no literal, del ítem propuesto teléfono móvil. Esto entra en relación con el proceso de descodificación, propio de la comunicación humana, que lleva al receptor a realizar

\footnotetext{
${ }^{3}$ Los informantes elegidos para las muestras pertenecen a $6 .^{\circ}$ de EP, I. ${ }^{\circ}$ de ESO y $2 .^{\circ}$ de ESO, y en total suman I5I informantes. Son alumnos del Centro concertado Santa María del Carmen, sito en la calle Misterios, n. ${ }^{\circ} 38$ de Madrid. En general, pertenecen a un grupo socioeconómico de nivel medio-bajo. La edad de los estudiantes se encuentra entre los II y los I5 años; el $60 \%$ son mujeres y el $40 \%$ hombres. Atendiendo a su nacionalidad, la procedencia de los alumnos presenta los siguientes porcentajes: españoles $61,59 \%$, latinos $31,13 \%$, chinos 1,99\%, filipinos I,99\%, rumanos $1,99 \%$, búlgaros $0,66 \%$ e hindúes $0,66 \%$. El nivel intelectual general es medio, aunque se caracteriza por cierta falta de motivación e interés hacia el estudio.
} 
determinadas inferencias sobre la información dada (Penas lbáñez y Alonso Perdiguero, 2010). En este caso, el texto del blog contiene información que restringe su posible campo semántico a lo técnico informático, aunque necesita de la competencia lingüística de los integrantes del corpus a la hora de deducir su significado, como se verá más adelante.

Asimismo, permite ver el grado de comprensión del texto que poseen los informantes y si las definiciones son parciales o completas, si difieren o no de las de los diccionarios de uso escolar o académico, o, por el contrario, convergen con las de ellos, a través de los distintos mecanismos de equivalencia empleados: hiperonimia-hiponimia, paráfrasis, reformulación (Penas Ibáñez y Abad Serna, 2011) y traducción intralingüística (Penas lbáñez, 2015a).

Esto posibilita tener a priori un amplio repertorio de definiciones de un mismo ítem léxico que va a permitir contrastar y comparar los datos recabados para llegar a conclusiones parciales sobre los elementos de estudio acerca de la comprensión textual y la capacidad de reformular, en cuanto que traducir intralingüísticamente, el contenido asimilado. Con respecto al nivel traductológico, el informante, traductor literal, descompone el texto en elementos simples (o en pequeños grupos de elementos) hipotéticamente equivalentes en la lengua de llegada. El informante, traductor libre, en cambio, juzga qué función cumple el texto completo en el discurso y busca los elementos que puedan cumplir esa función en la situación de la lengua de llegada. El acierto o desacierto de cada enfoque es imprevisible como se verá a lo largo de la investigación: una traducción intralingüística literal puede ser acertada o torpe e incluso ininteligible, mientras que otra libre puede ser adecuada o provocar que el texto original (el blog) se desintegre y desparezca completamente. Dado que a los estudiantes se les expone, raramente, a la tarea de ejecutar estrategias, su conocimiento de los sistemas virtuales sintácticos, gramaticales y léxicos será en principio de poco valor práctico, puesto que no lo relacionarán con los textos, con las situaciones, con los planes ni con las metas que caracterizan la interacción comunicativa textual.

Una vez obtenidos los datos, se pasa a analizar la información con el fin de sistematizarla y cuantificarla en relación con el léxico técnico-informático. Para ello, las definiciones se han agrupado por semas que conforman el contenido semántico nuclear. Así, se consigue una primera aproximación por el contenido semántico inicial, empleado por los informantes en las definiciones.

Se procede a hacer el estudio de un modo inductivo: $1 .^{\circ}$ ) se parte de la información contextual que ofrece la muestra del blog; $2 .^{\circ}$ ) se compara con la información lexicográfica que presentan las definiciones del término teléfono móvil, y $3 .^{\circ}$ ) se finaliza con la definición aportada por los informantes. En cuanto a la información lexicográfica, se comienza por los diccionarios escolares (SM, VOX y Diccionario del Estudiante Secundaria y Bachillerato, Santillana, en adelante DESB), que son los manejados mayoritariamente en las aulas, para después culminar el estudio contrastando lo definido 
por los informantes y lo inferido por el contexto de la muestra, con la información que dan los diccionarios generales (DLE, DUE y DEA), usados de manera complementaria.

Por último, se señala que, debido a la limitación de espacio, se hace mención en el artículo constantemente a unas muestras, objeto del presente estudio, que no se incluyen en su versión completa. Ahora bien, a lo largo del artículo va a aparecer un número determinado de definiciones que permiten, por un lado, mostrar los datos, aunque no todos, y por otro, mostrar los mecanismos semánticos empleados, donde se verá si son semejantes o diferentes entre los miembros que integran el corpus, si son acertados con respecto al texto donde se encuentra el término objeto de análisis, así como su aproximación o alejamiento con relación a las fuentes lexicográficas consultadas. La presencia de los datos es indispensable para señalar su procedencia, mostrar la información real disponible y el tratamiento que se realiza de ella.

Las definiciones se recogen de forma sistemática a lo largo del artículo: en primer lugar, está el informante asociado a un número en cursiva, que viene determinado por el orden de aparición dentro del artículo, puesto que por la ley de protección de datos no se puede mencionar la identidad del informante; a continuación, se señala entre paréntesis el curso al que pertenece; después, la definición del término, señalada entre comillas, y, por último, realizamos la extracción del contenido semántico marcado mediante los símbolos ", que nos va a permitir sistematizar dicho contenido para cuantificarlo y analizarlo con el objeto de llegar a unas conclusiones consistentes.

\section{| Información textual |}

El texto pertenece al blog de informática <http://informatica.centralblogs.com>. El término por definir es teléfono móvil y está en relación directa con el texto. El blog presenta la siguiente información por la que los informantes pueden aproximarse a la explicación del término, que subrayamos a continuación: "Como complemento perfecto a los teléfonos móviles de la marca de la manzana se han dado a conocer ya en el mercado unos altavoces. Se caracterizan por su diseño elegante y sofisticado que hace que quien los tenga, sin duda, presuma de los mismos".

En el texto aparece subrayada la expresión que se ha de definir teléfonos móviles, pero no hay ningún otro dato del texto que permita llegar directamente a su interpretación. También se han señalado complemento y altavoces, ya que se establece una relación semántica entre los tres elementos de hiperonimia-hiponimia entre complemento y altavoces, por incluirse el último en el primero, y en la de meronimia-holonimia entre altavoces y teléfonos móviles, por indicarse una parte respecto del todo. Estos elementos subrayados no permiten identificar en sí el objeto, aunque sirven para establecer sus componentes. De igual manera, son fundamentales su presentación, diseño elegante y sofisticado, y la consecuente reacción de las personas que poseen dicho aparato, quien los tenga... presuma de los mismos. La recurrencia en el uso de hiperónimos -y no de 
sinónimos - como mecanismo de definición por parte de los informantes es un claro indicador de que proceden de forma genérica, que en este caso no quiere decir por falta de precisión semántica y/o de riqueza léxica, puesto que no es posible hallar en el español de España un sinónimo para tal expresión lexicalizada, aunque sí lo es en el español de América, dado que su denominación es teléfono celular. De ahí que recurran a hiperónimos los informantes, como así hace también una buena parte de los diccionarios consultados.

Cabe señalar, igualmente, una información cultural que se infiere de la interpretación de objeto comercial que ha sido diseñado en función de un futuro comprador/usuario: quien los tenga; y que de esta posesión se hace sobrentender la consecuencia que provoca en su dueño, presuma de los mismos. La reacción de su poseedor, de ser valorado socialmente por tener dicho objeto, viene fundamentada por la referencia a la marca del producto, manzana (Apple), cuyo conocimiento del mundo exterior indica que es cara y poco accesible económicamente a todos los bolsillos; y también, su forma, su presentación, diseño elegante y sofisticado, que provoca atracción, necesidad de posesión. Estas características aportan una especialización semántica que lo convierten en un tecnicismo de la mercadotecnia: 'objeto de marketing informático'. Todos los elementos mencionados tienen que ver con objetos que tienen necesidad de adoptar, tanto en su construcción como en su funcionamiento, herramientas surgidas de la investigación y aplicadas de forma industrial, por lo que necesitan de dicha tecnología para su existencia.

Por último, los teléfonos móviles se pueden portar porque poseen esta característica como rasgo relevante. Tanto es así que se produce una elipsis en la expresión lexicalizada, pasando el objeto a denominarse simplemente móvil, a través de la cualidad de poderse llevar a todas partes, y dejando en un segundo plano la denominación del aparato base, teléfono, y su función comunicativa.

La información textual analizada permite realizar el siguiente esquema en el que se trata de establecer los niveles de clasificación entre los distintos datos subrayados y su relación con el contexto; así, se aprecia la importancia tanto del conocimiento y la necesidad de la competencia lingüística como de la posesión de la competencia comunicativa a través del conocimiento pragmático del mundo para la comprensión e interpretación de un texto. La relación entre los elementos sémicos viene marcada por los niveles jerárquicos de representación, y las interpretaciones pragmáticas - a partir de las expresiones del texto comentadas más arriba- aparecen subrayadas en el gráfico 1 (ver anexos).

\section{| Información lexicográfica |}

La expresión teléfono móvil propuesta para su definición consta de dos términos. En todos los diccionarios consultados, ya sean escolares o generales, aparece recogida como lexicalizada. Así, las fuentes lexicográficas escolares recogen las siguientes 
acepciones: en SM, "el que no tiene cables y se puede llevar de un sitio a otro" $\underline{\text { of; }}$ en la acepción cuarta de DESB, "aparato telefónico pequeño que no tiene hilos ni cables externos y que está en contacto con una red de estaciones mediante una señal que emite y que permite hablar por él desde cualquier punto que esté dentro de su cobertura"; y en VOXonline, "aparato telefónico de pequeño tamaño, portátil, sin hilos ni cables externos, para poder hablar desde cualquier lugar, siempre que sea dentro del área de cobertura del servicio que lo facilita”.

La información lexicográfica permite sintetizar la información con los semas coincidentes y divergentes de las fuentes escolares consultadas, tal como se constata en el gráfico 2 (ver anexos).

SM no menciona 'aparato', sino que lo indica anafóricamente a través de la elisión del antecedente de un pronombre relativo, el que, cuyo referente es 'teléfono', que coincide con la entrada donde aparece el significado de la expresión lexicalizada teléfono móvil. Este diccionario pone de relieve en la definición la importancia del adjetivo móvil de la expresión, destacándose las cualidades intrínsecas de estos aparatos frente al objeto en sí, por lo que la definición se realiza de forma metonímica 'contenido por continente'. No se señala la utilidad de este instrumento, puesto que está bajo el lema teléfono; así, en la segunda acepción de este diccionario, "aparato para emitir y recibir comunicaciones sonoras a distancia".

Los diccionarios generales igualmente presentan la expresión teléfono móvil de forma unitaria al ser un compuesto sintagmático. Solo se encuentra el sema 'aparato' en el DLE: "aparato portátil de un sistema de telefonía móvil". En el DEA aparece la expresión dentro de la entrada de móvil, en la primera acepción 1.b): "[Teléfono] portátil incorporado a una red de transmisión de alta frecuencia. $T b n \mathrm{~m}$. Tb se aplica a la línea y a la telefonía correspondientes. Se opone a FIJO"; y, por último, en el DUE aparece: "el que funciona sin cable y está en contacto con una red de estaciones mediante una señal que emite, lo que permite efectuar o recibir llamadas en cualquier punto situado dentro de su cobertura. 1 Móvil”.

Como en el diccionario SM, también en el DUE se hace referencia a estos aparatos a través de un pronombre relativo con elipsis del antecedente, puesto que su referencia anafórica es la entrada donde está situada dicha expresión, es decir, teléfono. En la definición que aparece en el $D E A$, se ha comentado que viene dentro del adjetivo móvil; de esta forma se priman las cualidades — que sí aparecen dentro de la definición — frente al objeto. Aunque se procede tautológicamente a través de la expresión que es motivo de definición, esta sí resulta clarificadora al valerse del antónimo, se opone a FIJO.

La información lexicográfica de los diccionarios generales ha permitido, como en el caso de los textos escolares, realizar su agrupación semántica en una tabla donde se pueden ver los rasgos sémicos de las definiciones coincidentes o/y divergentes, así como

${ }^{4}$ Los subrayados que aparecen a lo largo del artículo en las fuentes lexicográficas consultadas son nuestros. 
ausentes. Estos serán fundamentales, cuando analicemos las propuestas aportadas por los informantes, para ver el grado de acercamiento o alejamiento a dichas fuentes léxicas. Esto se puede observar en el gráfico 3 (ver anexos).

Dichos diccionarios generales coinciden en marcar, como elemento caracterizador, la portabilidad y el pertenecer a una red/sistema de comunicación. Si comparamos estas fuentes con las escolares, se aprecia que coinciden en la portabilidad. Aunque el DESB solo hace referencia a que el teléfono móvil "no tiene hilos ni cables", se infiere que se puede llevar a cualquier sitio por no estar sujeto. En cuanto a la necesidad de estar incluido dentro de un sistema para su función -lo que es un dato común en los textos lexicográficos generales-, esto solo aparece en DESB.

\section{| Semas definicionales |}

El resultado de las muestras analizadas, 151 definiciones que suponen el $100 \%$ de la cuantificación, revela que 'aparato' (con un 34,21\%), 'teléfono' (con un 15,13\%), 'objeto' (con un 13,82 \%), 'llamar' (con un 4,61\%) y 'medio' (con un 4,61\%) son los semas elegidos por los informantes como primera aproximación a la explicación definicional del término teléfono móvil. Hemos incluido un apartado otros (con un 16,45\%) para aquellas definiciones que no reúnen un número considerable de muestras como para formar uno independiente. Además, dentro de estas muestras hay un número de informantes que no contestaron (11,18\%). Si se observa el porcentaje de los datos, se aprecia que el sema 'aparato' es el más utilizado por los informantes con una gran diferencia respecto de los demás.

\section{Sema 'aparato'}

Los datos ofrecen los siguientes resultados por orden de frecuencia de uso: 'aparato + electrónico' (10 6,6\%), 'aparato + comunicar' (9 6\%), 'aparato + hablar' (9 6\%), 'aparato + inalámbrico' (6 4\%), 'aparato + llamar' (5 3,3\%), 'aparato + pequeño' (5 $3,3 \%)$, 'aparato + no cables' $(2 \sim 1,3 \%)$, 'aparato + contactar + personas' $(1 \sim 0,7 \%)$, 'aparato + eléctrico + llamar' (1 0,7\%), 'aparato + portátil + llamar' (1 0,7\%), 'aparato + receptor + transmisor + llamar' (1 0,7\%), 'aparato + rectangular + oír + personas' $(1$ $\sim 0,7 \%)$ y 'aparato + telecomunicación + funcionar + sin enchufar' $(1 \sim 0,7 \%)$.

Los dos valores numéricos aportados entre paréntesis responden al número de definiciones que recoge ese etiquetaje semántico, con respecto a la primera cifra, y al porcentaje parcial de la representación total, es decir, al 34,21\% de las definiciones del ítem analizado, referente a la segunda cifra, con un total de 51 informantes, coincidentes con otros (46) y no coincidentes con otros (5). 
Aunque el término propuesto para su definición consta de dos palabras, los informantes se han aproximado al concepto por una de ellas, teléfono. En los datos ofrecidos anteriormente se comprueba que la elección preferida para su definición se realiza a través de la relación semántica de hiperonimia-hiponimia, donde 'aparato' incluiría teléfono móvil. El uso de hiperónimos -y no de sinónimos-como mecanismo de definición por parte de los informantes es un claro indicador de que proceden de forma genérica, que, en este caso, no quiere decir por falta de precisión semántica y/o de riqueza léxica, puesto que no es posible hallar en el español de España un sinónimo para tal expresión lexicalizada, aunque sí lo es en el español de América, dado que su denominación es teléfono celular. De ahí que los informantes recurran a hiperónimos, como así hace también una buena parte de los diccionarios consultados.

El concepto 'aparato' se asocia con la utilidad 'servir para', es decir, con un instrumento. Dicho sema aparece acompañado de más elementos para especificar su definición, como se verá a continuación, y así intentar precisar al máximo el significado de la expresión teléfonos móviles. El sema 'aparato' se va a asociar con semas que responden a su finalidad, como 'comunicar', 'hablar', 'llamar', 'contactar' y 'receptor', y también a sus propiedades o características, como 'electrónico', 'inalámbrico', 'pequeño', 'no cables', 'eléctrico', 'portátil', 'rectangular' y 'telecomunicación'. De esta manera, el sema nuclear 'aparato' viene acompañado de los contenidos referentes a su función y a sus características, ya sean de tamaño, de independencia, de forma, de alimentación, etc., que permiten especificarlo.

En todas las muestras del corpus relativas al sema primero 'aparato', 51 en total $(40,18 \%)$, todos los informantes lo han relacionado con su función en algún momento de la definición, menos en dos casos. Preferentemente, se han valido de la metonimia para explicar la intensión del primer sema clasificador; de esta manera, la utilidad va a servir para restringir la amplitud semántica del hiperónimo.

Los semas elegidos son 'llamar', 'comunicar' y 'hablar'. Entre ellos se establece una relación semántica de sinonimia en el contexto de la telefonía, propiamente en el caso de 'comunicar' y 'hablar' y por presuposición, en el caso de 'llamar', puesto que llamamos para hablar o comunicar algo. A propósito de la posición del ejecutor de la acción, son curiosos los semas minoritarios de 'contactar' y 'oír a personas', donde el foco significativo se sitúa en la interacción con el receptor de la llamada: contactamos con él y le oímos. Con estas definiciones, se señala la reciprocidad de la comunicación telefónica. Así, se puede ver en las siguientes muestras:

Informante 1 (1. B): "Aparato que sirve para contactar con otras personas", 'aparato + contactar + personas'.

Informante 2 (6. A): "Aparato rectangular que sirve para oír a las personas", 'aparato + rectangular + oír + personas'. 
A continuación, se muestran las dos definiciones que no señalan la función en el sema primero 'aparato', sino que se valen para acotar el significado del hiperónimo de características descriptivas de los teléfonos móviles como son 'inalámbrico' o 'funcionar + sin enchufar'.

Informante $3\left(1 .^{\circ} \mathrm{B}\right)$ : “Son aparatos inalámbricos”, 'aparato + inalámbrico'.

Informante 4 (6. $\mathrm{A})$ : "Aparato de telecomunicación que no necesita estar enchufado para funcionar", 'aparato + telecomunicación + funcionar + sin enchufar'.

El uso de semas asociados con la descripción de teléfono móviles es frecuente en las muestras, las cuales también han registrado su función. Así, se han elegido unas cuantas definiciones con las que dar cuenta de la competencia lingüística y comunicativa de los informantes para intentar concretar al máximo el significado del término propuesto.

Informante $5\left(2 .^{\circ} \mathrm{A}\right)$ : “Aparato portátil que sirve para llamar y muchas más utilidades", 'aparato + portátil + llamar + más utilidades'.

Informante $6\left(6 .^{\circ} \mathrm{A}\right)$ : "Aparato que permite llamar a otras personas sin necesidad de ir a casa”, 'aparato + llamar + no ir + casa'.

Informante $7\left(1 .^{\circ} \mathrm{A}\right)$ : "Son unos aparatos electrónicos pequeños, que sirve para llamar desde cualquier lugar”, 'aparato + electrónico + llamar + cualquier lugar'.

Informante 8 (2. A): "Es un aparato electrónico, con él se puede hablar (a través de él) con otra persona, enviar mensajes... y demás. En este caso es transportable y ligero”, 'aparato + electrónico + hablar/enviar mensajes + transportable + ligero'.

Informante $9\left(2{ }^{\circ} \mathrm{A}\right)$ : “Aparatos que utilizamos para hablar y más cosas, se pueden transportar", 'aparato + hablar + transportar'.

Informante 10 (2..$^{\circ}$ B): "Son aparatos mediante los cuales puedes hablar con alguien que esté a distancia sin estar en lugar concreto", 'aparato + hablar + a distancia + sin lugar concreto'.

Informante $11\left(1{ }^{\circ} \mathrm{A}\right):$ "Aparato sin cables que sirve para hablar en distancias larga o corta", 'aparato + no cables + hablar + distancia larga/corta'.

Informante 12 (2. $\left.{ }^{\circ} \mathrm{B}\right)$ : "Son aparatos pequeños que se utiliza para poder comunicarse desde larga distancia o estando cerca", 'aparato + pequeño + comunicar + distancia larga/cerca'.

Informante $13\left(1 .^{\circ} \mathrm{B}\right)$ : "Aparato que sirve para comunicarse si lo necesitas (también tiene juegos, música, etc...)”, 'aparato + comunicar + juegos/ música'. 
En la muestra 3 se ha señalado como elemento identificador de teléfono móvil 'inalámbrico'; en la 5, 'portátil'; en la 8, 'transportable y ligero'; en la 9, 'transportar'; en la 11, 'sin cables', y en la 12, 'pequeño'. Son características propias del aparato que vienen marcadas ya en la entrada móvil. Los informantes emplean un hiperónimo clasificador de este objeto, aparato, $y$, a continuación, se valen de términos sinónimos de la segunda parte del formante de la entrada por definir. Así, 'inalámbrico' $\approx$ 'portátil' $\approx$ 'transportable y ligero' $\approx$ 'transportar'. Las siguientes otras características: 'sin cables' y 'pequeño', incluso 'ligero' de la definición 8, se sobrentienden, ya que no puede tener cables para que permita ser llevado de un sitio a otro y le asisten las dos propiedades de 'ligero' y 'pequeño' para ser manejable en su transporte.

En relación con el hecho de ser portable, es otra propiedad que proporcionan las muestras elegidas del corpus, como se advierte en la muestra 6 'no ir + casa' y en la 7 'cualquier sitio', donde se señala que estos aparatos permiten realizar su función sin estar asociado a un lugar específico. De ahí la presuposición realizada por los informantes, puesto que pueden ser llevados de un lugar a otro, no necesitan estar en casa y es indiferente la coordenada espacial, ya que se puede usar en cualquier lugar.

Otro dato asociado a esta dimensión es la lejanía o la cercanía del receptor de la llamada con respecto al emisor. En la muestra 10 aparece 'a distancia + sin lugar concreto'; en la 11, 'distancia larga/corta' y en la 12, 'distancia larga/cerca'. Estas dos últimas emplean dos semas para explicar dicha característica de los teléfonos, donde el primer elemento empleado ('larga') es el mismo; sin embargo, en el segundo hay una variación cuasisinonímica ('corta, cerca').

Por último, en algunas definiciones se señala que con este aparato se pueden realizar otras funciones, además de llamar. En el breve muestreo seleccionado del total del corpus, se puede apreciar en la número 5 'más utilidades', en la 8, 'enviar mensajes' y en la 13, 'juegos/música'. Según estas muestras, se procede de lo general y poco concreto de la muestra 5 a lo cada vez más específico en las otras dos; en la 8 observamos que otra función sería la posibilidad de enviar mensajes, la cual entra dentro de la esfera de la comunicación y conecta con la 'utilidad' principal señalada por los informantes como se ha visto con anterioridad - en los semas cuantitativamente mayoritarios que acompañan a 'aparato'. Sin embargo, la muestra 13 indica otras aplicaciones lúdicas de los teléfonos móviles que no tienen que ver con la función principal de la intercomunicación, como son los juegos y la música, aunque sí con la interacción.

En el gráfico 4 (ver anexos) se recogen las preferencias mayoritarias de los informantes para explicar el concepto teléfono móvil:

Al principio del análisis del concepto teléfono móvil se pudo observar que el sema 'aparato' era utilizado por una mayoría significativa de informantes en sus definiciones. Esto supone un acierto al ser uno de los semas atestiguados en la mitad de los diccionarios consultados, junto con el otro que es 'teléfono', sustituido anafóricamente por el que. 


\section{Sema 'teléfono'}

El sema 'teléfono' aparece en el corpus siempre asociado a otros semas en su definición. Por orden de frecuencia de uso: 'teléfono + llevar' (7 4,6\%), 'teléfono + pequeño' (5 $\sim 3,3 \%)$, 'teléfono + no cables' (3 2\%), 'teléfono + inalámbrico' $(2 \sim 1,3 \%)$, 'teléfono + independiente' $(1 \sim 0,7 \%)$, 'teléfono + manejar + fuera + no cables' $(1 \sim 0,7 \%)$, 'teléfono + móvil + máquina + comunicar + distancia' (1 0,7\%), 'teléfono + objeto + hablar + mover' $(1 \sim 0,7 \%)$, 'teléfono + portátil' $(1 \sim 0,7 \%)$ y 'teléfono + no dispositivo eléctrico' $(1 \sim 0,7 \%)$.

Los dos valores numéricos aportados entre paréntesis responden al número de definiciones que recogen ese etiquetaje semántico, con respecto a la primera cifra, y al porcentaje parcial de la representación total, es decir, del 15,13\% de las definiciones del ítem analizado, referente a la segunda, con un total de 23 informantes, coincidentes con otros (17) y no coincidentes con otros (6).

Los informantes intentan definir la expresión a partir de su segundo término, móvil, puesto que no realizan ningún tipo de transformación con respecto al primer miembro, que utilizan sémicamente tal cual. Incluso, en la definición del informante 14 se aprecia que se ha sustituido el primer término de la expresión teléfono móvil, mediante un equivalente por hiperonimia- hiponimia, máquina $\simeq$ teléfono, a la que se le añaden los datos de su finalidad, 'comunicación' y de su alcance, 'distancia':

Informante $14\left(2 .^{\circ} \mathrm{B}\right)$ : “El teléfono móvil es una máquina con la que poder comunicarte con otra persona sin importar la distancia", 'teléfono + móvil + máquina + comunicar + distancia'.

Otra definición que identifica teléfono con un hiperónimo de rango superior: 'objeto', acompañado de datos como finalidad, 'hablar', y transportabilidad, 'mover', es la siguiente:

Informante $15\left(2 .^{\circ} \mathrm{A}\right)$ : "Es un teléfono (objeto con el que puedes hablar) que se puede mover", 'teléfono + objeto + hablar + mover'.

Otro aspecto destacado es su conexión ('inalámbrico' + 'no dispositivo eléctrico' + 'no cables'), como se ve en las siguientes definiciones:

Informante $16\left(2 .^{\circ} \mathrm{A}\right)$ : "Teléfono que no necesita un dispositivo eléctrico para su funcionamiento”, 'teléfono + no dispositivo eléctrico';

Informante $17\left(10^{\circ} \mathrm{A}\right)$ : "Teléfono que no necesita cables, va por cobertura", 'teléfono + no cables + cobertura'; 
Informante 18 (1. $\mathrm{B})$ : "Teléfonos inalámbricos que se pueden llevar por ahí, no necesitan ser enchufados", 'teléfono + inalámbrico + llevar + no enchufar'.

Otra característica empleada por los informantes para explicar la intensión del sema es su localización 'fuera', como vemos a continuación:

Informante 19 (1. $\mathrm{B})$ : "Es un teléfono que se puede manejar fuera de casa y no tiene cable”, 'teléfono + manejar + fuera + no cables'.

También aparecen las referencias a su tamaño, 'pequeño':

Informante 20 (1. A): "Teléfonos pequeños para poder ser transportados", 'teléfono + pequeño + transportar'.

Informante 21 (6. A): “Teléfono pequeño que se lleva en el pantalón”, 'teléfono + pequeño + llevar'.

Por lo tanto, los informantes intentan definir la expresión a través de la identificación de características propias, ya que el sema 'teléfono' empleado no resulta suficientemente clarificador al ser un elemento que forma parte de la propia expresión por definir. Se ha visto en los ejemplos señalados que en muchas ocasiones aparecen varias características, no solo una. De alguna manera, esta especificación a través de las propiedades ya se había visto en el sema anterior, 'aparato'.

Con relación al texto dado a los informantes para definir teléfono móvil, recordemos que el sema 'teléfono' aparece de forma explícita, pero no hay ningún otro dato del texto que permita llegar directamente a la interpretación de teléfono. Por otra parte, se encuentra altavoces, con lo que se puede sobrentender 'complemento del teléfono' al no ser únicamente un complemento de los teléfonos, puesto que puede serlo, igualmente, de un reproductor, de un $\mathrm{mp} 3$, etc.

En cuanto a la información lexicográfica, en los diccionarios consultados el sema 'teléfono' aparece en las definiciones recogidas bajo la expresión lexicalizada de teléfono móvil. Con respecto a las fuentes lexicográficas escolares, no se localiza de forma explícita 'teléfono' en el diccionario SM, donde se entiende que lo importante son las características, no el objeto en sí al que se hace referencia a través del anafórico el que; pero en los otros dos diccionarios escolares sí se menciona: en DESB y en VOX online. En ambos tratados aparece la referencia a teléfono a través de una estructura sintagmática formada por un hiperónimo aparato + un adjetivo especificativo telefónico, de la misma raíz léxica que la del término que se ha de definir. De esta manera, la definición tiene un comienzo tautológico, puesto que el término definido entra en la definición; sin embargo, si se observa todo el desarrollo definicional, se aprecia que en los dos diccionarios se señalan las características específicas de estos objetos, por lo que ese principio de coincidencia homoléxica de ambos términos está fundamentado en las diferencias funcionales del objeto. 
Los diccionarios generales DLE y DEA también ofrecen en la definición de la expresión lexicalizada la referencia al sema 'teléfono' 5 .

En el $D U E^{6}$ se encuentra también la referencia a teléfono a través del anafórico y señalan como pertinentes las características que permiten identificar el objeto y la referencia al aparato a través de móvil. Esta identificación de las fuentes lexicográficas conecta con la realizada por los informantes a través de las propiedades que posibilitan su diferenciación.

\section{Sema 'objeto'}

El sema 'objeto' presenta un contenido que designa una realidad muy general, siendo un hiperónimo de rango superior de teléfono móvil, su hipónimo. Se necesita, por tanto, de otros términos que ayuden a limitar la clase designativa de este primer sema tan genérico 'objeto'. Esto indica también la necesidad de búsqueda de exactitud y precisión semántica por parte de los informantes. Los datos, ordenados por frecuencia de uso, son los siguientes: 'objeto + llamar' (8 5,3\%), 'objeto + comunicar' (5 3,3\%), 'objeto + hablar' (3 2\%), 'objeto + electrónico' ( 2 1,3\%), 'objeto + hacer + llamada' (1 $0,7 \%)$, 'objeto + llevar + hablar + cobertura' $(1 \sim 0,7 \%)$ y 'objeto + recibir/mandar + llamadas/mensajes' (1 0,7\%).

Los dos valores numéricos aportados entre paréntesis responden al número de definiciones que recogen ese etiquetaje semántico, con respecto a la primera cifra, y al porcentaje parcial de la representación total, es decir, del 13,82\% de las definiciones del ítem analizado, referente a la segunda, con un total de 21 informantes, coincidentes con otros (18) y no coincidentes con otros (3).

Se observa un predominio absoluto de definiciones que destacan la utilidad o finalidad del 'objeto'. No aparece siempre el mismo término, sino que se comprueba el uso de cuasisinónimos dentro del campo semántico de los verbos dicendi, como 'llamar' 'comunicar' 'hablar', como se puede constatar en los siguientes ejemplos:

Informante $22\left(2 .^{\circ} \mathrm{A}\right)$ : "Objeto con el que se puede llamar a otra a larga distancia ya que no tiene cables", 'objeto + llamar + distancia + no cables';

\footnotetext{
5 En el DLE se lee: "aparato portátil de un sistema de telefonía móvil" y en el DEA: "[Teléfono] portátil incorporado a una red de transmisión de alta frecuencia. Tb n m”. Tb se aplica a la línea y a la telefonía correspondientes. Se opone a FlJO”; esta última definición aparece dentro de la entrada móvil, en la acepción I.b) y así, esta fuente lexicográfica justifica que lo esencial del instrumento son sus características; por ese motivo se encuentra dentro del adjetivo y no del sustantivo teléfono, como sucede en los otros diccionarios. Además, señala el uso generalizado del término en la actualidad, puesto que la forma de nombrar este objeto es, por elipsis, a través del adjetivo móvil que se ha sustantivado. En el subrayado de las definiciones de ambos diccionarios se observa de nuevo la coincidencia homoléxica entre la definición (definiens) y el término por definir (definiendum), como en los escolares, destacándose otra vez la importancia de las características específicas.

6 La entrada del DUE dice: "el que funciona sin cable y está en contacto con una red de estaciones mediante una señal que emite, lo que permite efectuar o recibir llamadas en cualquier punto situado dentro de su cobertura. I Móvil”, donde se señala como función diferencial del aparato, el efectuar o recibir llamadas en cualquier punto situado de su cobertura.
} 
Informante 23 (2. ${ }^{\circ}$ B): "Objeto electrónico que se utilizan para comunicarse con los demás”, 'objeto + electrónico + comunicar’;

Informante $24\left(1 .^{\circ} \mathrm{A}\right)$ : "Objeto que sirve para poder hablar con las personas a distancia", 'objeto + hablar + distancia'.

También asociado al concepto de utilidad se encuentran mecanismos perifrásticos de sinonimia como 'objeto + llamar' $\rightarrow$ 'objeto + hacer + llamada', para expresar el mismo significado, por ejemplo, en:

Informante $25\left(1 .^{\circ} \mathrm{A}\right)$ : "Objeto electrónico que sirve para hacer llamadas desde cualquier sitio que no sea necesario estar en casa", "objeto + electrónico + llamar + cualquier sitio'.

Finalmente, se ha de destacar la definición de un informante en la que el sema 'objeto' relacionado con su empleo ofrece la posibilidad inversa en cuanto a su utilidad; así, 'objeto + recibir/mandar + llamadas/mensajes', donde no solo se señala la posibilidad de comunicación con voz sino mediante textos escritos, a través de los antónimos inversos: 'recibir/mandar (+ llamadas/mensajes)':

Informante $26\left(2 .^{\circ} \mathrm{A}\right)$ : "Objeto con el que se pueden recibir y mandar llamadas y mensajes", 'objeto + recibir/mandar + llamadas/mensajes'.

Al sema 'objeto' los informantes han podido llegar a través de los términos del texto: complemento, teléfonos móviles, manzana, altavoces, diseño elegante y sofisticado, quien los tenga... presuma de los mismos. Estos términos marcados responden a elementos inanimados, de fabricación humana, e independientes; por otra parte, teléfonos móviles y altavoces mantienen una compleja relación semántica con respecto a complemento y objeto: una triple relación inclusiva, donde altavoces sería el hipónimo de complemento y este a su vez el hipónimo de objeto y una doble relación de parte-todo, en la que altavoces sería el merónimo de teléfonos móviles, su holónimo.

Cabe señalar, igualmente, una información cultural que se infiere de 'objeto', consistente en que como objeto comercial ha sido diseñado en función de un futuro comprador/usuario y su valoración social por tener dicho objeto que viene fundamentado por la marca del 'objeto', como ya se señaló anteriormente cuando hablamos de la información textual.

La expresión que se ha de definir consta de dos términos que, en todos los diccionarios consultados, tanto escolares como generales, aparece recogida como lexicalizada. Los informantes han empezado por el sema 'objeto', que no está presente en los diccionarios, aunque sí 'aparato', en DESB y en VOXonline. Estos semas comparten una parte del espectro semántico, ya que, aunque 'aparato' tiene asociado el concepto de 'servir para', que no lo tiene 'objeto', al ser su significado más amplio, incluye 'aparato'. Recuérdense, al respecto, las definiciones ya comentadas que comienzan por el sema 'objeto', acompañado del rasgo finalidad y/o la descripción de sus características. Por 
último, en SM aparece la referencia a estos aparatos a través de un pronombre relativo con la elisión del antecedente, el que.

Los diccionarios generales también presentan la expresión teléfono móvil de forma unitaria, al ser un compuesto sintagmático, no encontrándose el sema 'objeto' en ninguna de ellas. Así, en el DLE, aparece 'aparato'; en el DEA, dentro de la entrada de móvil, '[Teléfono]'; y en el DUE, como se ha comprobado ya en el diccionario SM, se refiere a estos aparatos a través de un pronombre relativo, con elisión del antecedente, puesto que su referencia anafórica es la entrada donde se sitúa el primer término de dicha expresión, es decir, teléfono. En dicho diccionario sí aparecen las características y la finalidad de tal 'objeto'.

\section{Sema 'medio'}

Este sema presenta un contenido que refiere a una realidad muy variada y poco concreta. En todos los casos que aparece se utiliza asociado al de 'comunicar' ( $3 \sim 2 \%)$, hecho que revela que los informantes han destacado por encima de todo su principal finalidad. En cuanto a las otras definiciones, donde aparecen más semas acompañando a 'medio + comunicar', se tienen en cuenta las características de portabilidad de estos aparatos como puede ser 'inalámbrico' (1 0,7\%), 'llevar + pequeño' (1 0,7\%), 'portable + llevar + lugar' $(1 \sim 0,7 \%)$ y ‘hablar + sitio' (1 0,7\%).

Los dos valores numéricos aportados entre paréntesis responden al número de definiciones que recogen ese etiquetaje semántico, con respecto a la primera cifra, y al porcentaje parcial de la representación total, es decir, del 4,61\% de las definiciones del ítem analizado, referente a la segunda cifra, con un total de 7 informantes, coincidentes con otros (3) y no coincidentes con otros (4).

En este sema se localizan dos definiciones pleonásticas, en cuanto que se procede por reformulación parafrástica en 'portable $\simeq$ llevar + lugar' y en 'medio + comunicar $\simeq$ hablar + sitio'. Ello se advierte en:

Informante 27 (2. A): "Medio por el cual las personas se comunican y puede ser portable para llevar a cualquier lugar”, 'medio + comunicar + portable + llevar + lugar'.

Informante 28 (6. $\mathrm{A})$ : "Medio de comunicación con el que se puede hablar en cualquier sitio", 'medio + comunicación + hablar + sitio'.

El elemento del blog por el que los informantes han podido llegar al sema 'medio' es teléfono móvil, que es el ítem propuesto para su definición. Además, el conocimiento del mundo exterior que tienen de este pone de manifiesto que conocen el aparato y su uso forma parte de su realidad cotidiana. Resulta significativo el procedimiento metonímico 
(la finalidad o uso por el aparato u objeto) de abordar la definición de la expresión lexicalizada en las muestras relacionadas con este sema.

En los diccionarios escolares aparece el sema 'medio' en la primera acepción del término teléfono, tanto de forma inferida como de forma directa; en SM: "sistema eléctrico de comunicación a distancia que permite la transmisión de la palabra o de cualquier tipo de sonido a través de hilos conductores"; en DESB: "sistema de telecomunicación que consiste en la emisión, transmisión y recepción de sonidos o de cualquier otro tipo de señales, por medios eléctricos o electromagnéticos"; y en VOXonline: "sistema de comunicación que transmite la voz $y$ el sonido a larga distancia por medios eléctricos o electromagnéticos". En todos ellos podría interpretarse sistema como elemento cuasisinónimo de "medio". Tanto 'medio' como sistema responden al hecho de poder establecer contacto entre las personas y comunicarse, de ahí se infiere la generalización mediante estos dos conceptos para señalar los distintos tipos de comunicación. Dicha generalización se ve, a su vez, concretada en los dos últimos diccionarios en dos tipos de medios: eléctricos o electromagnéticos, que desde otro punto de vista al reflejado en los diccionarios podrían ser términos hiperónimos de teléfono (móvil).

En cuanto a los diccionarios generales consultados, en el DLE: 'conjunto de aparatos e hilos conductores con los cuales se transmite a distancia la palabra y toda clase de sonidos por la acción de la electricidad'; en el DEA: 'sistema de transmisión de sonidos a distancia, normalmente por medio de la electricidad'; y en el DUE: 'sistema de telecomunicación por medio de cables u ondas electromagnéticas, aplicado a la transmisión de sonidos', se comprueba que el DEA y el DUE se valen del mismo término que los diccionarios escolares, sistema, del que ya se ha indicado antes su grado de equivalencia semántica. Estos diccionarios también presentan su finalidad: transmitir sonidos a distancia. El DLE se enfrenta a la explicación del concepto teléfono de forma distinta al resto, valiéndose del contenido del término conjunto para expresar los elementos que integran este 'medio' o sistema que lleva a establecer contacto unas personas con otras, es decir, a llamarse. Se trataría más bien de una sinécdoque, todoparte: conjunto de aparatos e hilos conductores por teléfono. En cuanto a su finalidad, aparece léxicamente igual a la de los otros diccionarios generales: transmitir a distancia la palabra y toda clase de sonidos.

\section{Sema 'llamar'}

El sentido conceptual base del sema 'llamar' está recogido en el sema anterior 'medio + comunicar', $y$, al igual que en este, o bien puede aparecer solo (4 2,6\%), como único sema, o bien con más semas acompañantes que permiten hacer a los informantes una definición más completa: 'gente + buscar + información' (1 0,7\%), 'juegos' (1 0,7\%) y 'hablar' ( $1 \sim 0,7 \%)$; en este último caso se insiste en su función comunicativa ya señalada en el primer sema 'llamar'. 
Los dos valores numéricos aportados entre paréntesis responden al número de definiciones que recogen ese etiquetaje semántico, con respecto a la primera cifra, y al porcentaje parcial de la representación total, es decir, del 4,61\% de las definiciones del ítem analizado, referente a la segunda cifra, con un total de siete informantes, coincidentes con otros (4) y no coincidentes con otros (3).

Con 'llamar', los informantes ponen de relieve la intencionalidad de la persona que decide utilizar este aparato; pero no la de recibir las llamadas, dado que no solo uno es agente que decide actuar, sino que también se puede ser objeto destinatario de la ejecución de la llamada de otra persona. Ello se pone en evidencia en esta muestra:

Informante 29 (2. ${ }^{\circ}$ B): "Sirven para llamar a gente y hablar con ellos", 'llamar + hablar'.

El teléfono evidencia la circunstancia de la reciprocidad comunicativa que no se ha tenido en cuenta en las muestras definicionales. De los dos antónimos inversos ('llamar/recibir'), ha sido focalizado el primero, probablemente porque 'llamar' está en función de un 'recibir', sobrentendiéndose una secuenciación temporal unidireccional: 'antes $\rightarrow$ después', que bien puede evolucionar a una bidireccionalidad temporal: 'antes (yo/tú) $\leftrightarrow$ después (tú/yo)', dada la relación inversa que actualizan los actantes en ese contexto enunciativo.

En las dos muestras que señalamos a continuación se indican otras posibles funciones de los teléfonos móviles: 'buscar información' y ‘juegos':

Informante 30 (2. A): "Sirven para llamar a la gente, buscar información”, 'llamar + gente + buscar información';

Informante 31 (2. $\left.{ }^{\circ} \mathrm{A}\right)$ : “Sirven para llamar, juegos, etc.”, 'llamar + juegos'.

Los informantes han llegado a esta interpretación por su conocimiento del mundo; de ahí que, a través de un proceso de base metonímica, donde se destaca su uso, 'llamar', se pretenda llegar al aparato que posibilita tal función.

El sema 'llamar' no aparece en las fuentes lexicográficas consultadas; sí aparece, en cambio, la referencia a la finalidad de estos objetos: establecer contacto entre las personas. En consecuencia, el grupo de estos siete informantes aborda la definición por su utilidad y no por sus características.

En los diccionarios escolares se ha consultado en primer lugar por la expresión lexicalizada teléfono móvil; así, en $S M^{7}$ no hay referencia a su utilidad, solamente se

\footnotetext{
${ }^{7}$ Recuérdense las definiciones de la expresión lexicalizada que ofrecen los diccionarios escolares. En SM, "el que no tiene cables y se puede llevar de un sitio a otro"; en DESB, "aparato telefónico pequeño que no tiene hilos ni cables externos y que está en contacto con una red de estaciones mediante una señal que emite y que permite hablar por él desde cualquier punto que esté dentro de su cobertura"; y en VOX online, "aparato telefónico de pequeño tamaño, portátil, sin hilos ni cables externos, para poder hablar desde cualquier lugar, siempre que sea dentro del área de cobertura del servicio que lo facilita".
} 
muestran las características del objeto, que no tiene cables y se puede llevar de un sitio a otro, por lo que se necesita recurrir a la primera acepción del término teléfono ${ }^{8}$ para encontrar el concepto asociado a comunicación. Por consiguiente, este diccionario no diferencia los objetos por su utilidad, ya que el fijo y el móvil presentan la misma. La diferencia está en su característica de ser 'portátil'; de ahí que la referencia a la utilidad esté en la definición de la primera acepción de teléfono: "comunicación [...]" y "transmisión de la palabra o de cualquier tipo de sonido". Estos elementos pueden ser sustitutos parafrásticos funcionales de 'hablar/sonar'.

En los otros dos diccionarios, DESB y VOXonline, aparece la finalidad y las características del aparato dentro de la expresión lexicalizada teléfono móvil. En ambos casos se señala como elemento nuclear 'hablar', que no es lo mismo que 'llamar', aunque puede presuponerlo al considerar la necesidad de contactar para establecer una ulterior conversación (vid. nota 5). Ahora bien, cabe la posibilidad de proceder por sobrentendido si solo se presupone 'llamar', puesto que también se puede 'hablar' al 'recibir (una llamada)'.

En los diccionarios generales, se da una situación muy similar a la ya comentada en los escolares. Así, en el DLE, en teléfono móvil, no se menciona la finalidad, pero se hace referencia a través de telefonía al término teléfono, que en la primera acepción dice lo siguiente: "conjunto de aparatos e hilos conductores con los cuales se transmite a distancia la palabra y toda clase de sonidos por la acción de la electricidad". Se hace referencia a transmitir a distancia la palabra y toda clase de sonidos, presuponiendo un contacto previo. En el DEA, la expresión lexicalizada de teléfono móvil se encuentra en la entrada móvil, en 1.b): "[Teléfono] portátil incorporado a una red de transmisión de alta frecuencia. Tb n m. Tb se aplica a la línea y a la telefonía correspondientes. Se opone a FIJO”, donde se señala su utilidad, puesto que sirve para transmitir, es decir, comunicar, aunque lo realmente destacado es ser portátil. Por último, el DUE señala: "el que funciona sin cable y está en contacto con una red de estaciones mediante una señal que emite, lo que permite efectuar o recibir llamadas en cualquier punto situado dentro de su cobertura. 1 Móvil”. En él sí está expreso el sema 'llamar' en el sustantivo deverbal homoléxico llamada. Este diccionario registra el sema empleado por los informantes; además, lleva implícita una intencionalidad por parte de los hablantes en cuanto a efectuar (incluso recibir) llamadas.

\section{Otros}

En este apartado los semas más significativos son 'comunicar' ( 2 1,3\%), 'dispositivo' (3 2\%), 'instrumento' (4 2,6\%), 'llevar' (2 1,3\%), 'máquina + llamar' (2 1,3\%), 'móvil' (4 2,6\%) y 'tecnología' (2 1,3\%).

8 La primera acepción de la entrada teléfono del diccionario escolar SM señala lo siguiente: "sistema eléctrico de comunicación a distancia que permite la transmisión de la palabra o de cualquier tipo de sonido a través de hilos conductores". 
Los dos valores numéricos aportados entre paréntesis responden al número de definiciones que recogen ese etiquetaje semántico, con respecto a la primera cifra, y al porcentaje parcial de la representación total, es decir, del $16,45 \%$ de las definiciones del ítem analizado, referente a la segunda cifra, con un total de 19 informantes, coincidentes con otros (19) y no coincidentes con otros (0).

Estos datos se pueden relacionar con otros ya comentados más arriba; de esta forma, 'dispositivo', 'instrumento' y 'máquina + llamar' se vinculan con 'aparato' u 'objeto', respectivamente; el sema 'comunicar' está recogido en los semas 'medio' y en el sema 'llamar' y, por último, 'móvil' se relaciona con el sema 'teléfono', puesto que forma parte de la expresión que ha de definirse.

Por lo que respecta a 'llevar' y 'tecnología', no han aparecido de forma destacada para formar un apartado independiente, aunque sí están presentes en algunas definiciones como términos acompañantes para precisar el término que se ha de definir. Por ejemplo:

Informante 32 (2. A): "Son aquellos que se puede llevar a cualquier lugar", 'llevar + cualquier lugar';

Informante 33 (6. A): “Tecnología que se usa para estar en contacto”, 'tecnología + estar en contacto'.

En cuanto a la información empleada en este apartado OTROS, ya se ha visto que es coincidente por su significado, aunque no por su forma, puesto que aparece bajo otros semas equivalentes ('dispositivo', 'instrumento', 'máquina + llamar', 'comunicar', 'móvil'), que han ocasionado apartados diferenciados dentro del estudio de la expresión teléfonos móviles, como son 'aparato', 'objeto', 'medio', 'llamar' y 'teléfono'.

En cuanto a los semas 'llevar' y 'tecnología', los elementos del blog que han podido ocasionar en los informantes esta interpretación son complemento, teléfonos móviles, marca de la manzana, altavoces, diseño y sofisticado.

El sema 'llevar' es sinónimo de 'portar', presente en el adjetivo portátil que aparece explícito en algunas definiciones lexicográficas, como, por ejemplo, en el DEA. Se pueden portar los teléfonos móviles porque poseen esta característica como rasgo relevante. Tanto es así que se produce una elipsis de la expresión lexicalizada y el objeto ha pasado a denominarse simplemente móvil, a través de la cualidad de poderse llevar a todas partes, dejando en un segundo plano la denominación del aparato base teléfono y su función comunicativa. En cuanto al sema 'tecnología' se han destacado en el texto complemento, teléfonos móviles, marca de la manzana, altavoces y diseño sofisticado. Todos ellos tienen que ver con objetos que tienen necesidad de aplicar, tanto en su construcción como en su funcionamiento, herramientas surgidas de la investigación y aplicadas de forma industrial, por lo que necesitan de dicha tecnología para su existencia. Además de los objetos subrayados, se ha destacado el adjetivo sofisticado, puesto que, según el DLE, 3. a acepción, "dicho de un sistema o de un mecanismo: técnicamente 
Definición lexicográfica y discurso-textual de teléfono móvil

a partir de un blog

complejo o avanzado", lleva implícito el sema 'tecnología' en técnicamente complejo o avanzado.

En este apartado OTROS se han detectado definiciones de los informantes que ya se habían tratado dentro del estudio de teléfono móvil; por eso, se remite a los semas 'aparato', 'objeto', 'medio', 'llamar' y 'teléfono'. En cuanto a los semas 'llevar' y 'tecnología', no se han abordado todavía; de ahí que revisemos las distintas fuentes lexicográficas para justificar su empleo por los informantes.

En cuanto a los diccionarios escolares, en $S M$ se lee: "el que no tiene cables $y$ se puede llevar de un sitio a otro"; en DESB: "aparato telefónico pequeño que no tiene hilos ni cables externos y que está en contacto con una red de estaciones mediante una señal que emite y que permite hablar por él desde cualquier punto que esté dentro de su cobertura"; y en VOXonline: "aparato telefónico de pequeño tamaño, portátil, sin hilos ni cables externos, para poder hablar desde cualquier lugar, siempre que sea dentro del área de cobertura del servicio que lo facilita".

Se aprecia que el sema 'llevar' es utilizado de forma expresa en SM, o a través de otro sema sinónimo, 'portátil', como en VOXonline. Ahora bien, en todos los diccionarios escolares se puede inferir la portabilidad del objeto a través de los otros elementos marcados en las distintas definiciones. En este sentido, no tiene cables/no tiene hilos ni cables externos/sin hilos ni cables externos/desde cualquier punto/desde cualquier lugar. Estos elementos señalan el no estar sujeto a ninguna conexión física y también la disponibilidad de uso en cualquier lugar dentro de la red de cobertura de la compañía, por lo que se puede 'llevar' a todas partes. Sin embargo, se hace notar que los informantes no distinguen entre teléfono móvil propiamente y teléfono inalámbrico, en cuanto extensión de un teléfono fijo.

El sema 'tecnología' se puede inferir de los últimos elementos de las definiciones lexicográficas subrayadas, que tienen que ver con una infraestructura técnica necesaria que se deduce de 'sin cables ni hilos', por lo que presupone ser fruto de una investigación científica. Además, en DESB y en VOXonline aparecen referencias relativas a la pertenencia a un sistema más amplio de cobertura, necesario para el uso de estos aparatos, que también presupone el sema 'tecnología'. En DESB: "aparato telefónico pequeño que no tiene hilos ni cables externos y que está en contacto con una red de estaciones mediante una señal que emite y que permite hablar por él desde cualquier punto que esté dentro de su cobertura"; y en VOXonline: "aparato telefónico de pequeño tamaño, portátil, sin hilos ni cables externos, para poder hablar desde cualquier lugar, siempre que sea dentro del área de cobertura del servicio que lo facilita".

En relación con los diccionarios generales, se da una situación muy similar a la ya comentada en los escolares. Así, en el DLE aparece: "aparato portátil de un sistema de telefonía móvil”. EI DEA en la entrada móvil y en la primera acepción b): "[Teléfono] portátil incorporado a una red de transmisión de alta frecuencia. $T b n \mathrm{~m}$. Tb se aplica $a$ la línea y a la telefonía correspondientes. Se opone a FIJO”. Finalmente, el DUE señala: “el 
que funciona sin cable y está en contacto con una red de estaciones mediante una señal que emite, lo que permite efectuar o recibir llamadas en cualquier punto situado dentro de su cobertura. 1 Móvil”.

En el DLE y en el DEA aparece expreso el término portátil, que señala su característica más notoria de ser manejable y poder ser trasladado con facilidad, de ahí la reconstrucción interpretativa mediante 'llevar'; sin embargo, en el DUE, la llegada a este sema es a través del sobrentendido sin cable, puesto que supone 'no estar sujeto a ningún sitio' $\rightarrow$ 'no estar fijo' $\rightarrow$ 'llevar a todas partes', frente a inalámbrico; el sentido de este sema se produce por lectura preferente de uno de los dos antónimos que entraña la relación inversa: 'llevar/traer'.

En cuanto a la posible interpretación del sema 'tecnología', se ha subrayado telefonía en el $D L E$ y en el $D E A$, que supone la pertenencia a una ciencia concreta, la relacionada con la comunicación a distancia, que conlleva una investigación en las nuevas tecnologías para su desarrollo y su práctica. También, la relación de teléfono móvil con un sistema específico de conexión necesario para su funcionamiento; de este modo, en el DEA se señala una red de transmisión de alta frecuencia y en el DUE, una red de estaciones mediante una señal que emite, así como cobertura. Estos conceptos implican la puesta en práctica de una técnica y una tecnología en telecomunicaciones.

\section{| Conclusiones |}

Este estudio pone de manifiesto que la adquisición de la competencia lingüística, gramatical y lexicográfica, así como la comunicativa, discursiva y textual no se realiza de forma simultánea (Penas lbáñez, 2009); se puede entender un texto, pero pueden faltar estrategias comunicativas para explicarlo, como sucede con algunas de las muestras definicionales analizadas. Se observan tres grados de comprensión o reformulación del contenido textual: el primero sería el que señala una adecuada comprensión lectora o la identificación correcta de un término con otro, a pesar de que el informante no se plantee si realmente el término está aclarado o de que lo reproduzca sin reflexión; el segundo grado se daría cuando el informante ofrece una definición donde relaciona toda la información aportada por el blog, aunque no la reelabore puesto que utiliza las mismas palabras del texto; $y$, por último, el grado máximo de comprensión textual/reformulación, se encontraría cuando el informante, además de relacionar los distintos semas del texto del blog, es capaz de transformarlos con sus propias palabras y demostrar que conoce el significado del término.

Recordemos que los semas primigenios empleados por los informantes en sus muestras definicionales son los siguientes: 'teléfono', 'objeto', 'aparato', 'medio' y 'llamar'. El sema 'teléfono' indica un comportamiento tautológico en la explicación definicional, a pesar de que, como se ha indicado más arriba, siempre va acompañado de otros semas que 
intentan explicar el segundo miembro de la expresión, puesto que es el considerado por los informantes como nuclear -tanto es así que incluso se conoce por 'móvil', con elisión del primer elemento-. Estos semas acompañantes describen las características que sirven para distinguirlo del teléfono fijo, como son 'pequeño', 'llevar', 'independiente' o 'no cables'. En teléfono móvil se busca la equivalencia semántica a partir del segundo miembro ya que el primero es el clasificador genérico.

Los semas 'aparato', con un uso considerable, y 'objeto' mantienen una relación entre ellos de equivalencia parcial, teniendo en cuenta el contexto donde se encuentra inserta dicha expresión; ambos semas presentan una relación de hiperonimia ('objeto') / hiponimia ('aparato') entre sí, así como de hiperonimia con respecto a teléfono móvil, que sería su hipónimo. Los dos semas siempre van acompañados de más elementos que hacen referencia a su utilidad, como 'llamar' o 'contactar', o a sus características, como 'no cables'.

Por último, los semas 'medio' y 'llamar', aunque no comparten la misma categoría gramatical, sí participan de la referencia a la utilidad de teléfono móvil; en el caso de 'medio' siempre aparece acompañado del sema 'comunicar' para indicar claramente la finalidad o utilidad del objeto, por lo que la vía de aproximación en ambos casos es metonímica.

En cuanto a la información gramatical, los informantes han tendido a respetar y reproducir la categoría formal del término objeto de definición. Se ha comprobado que solamente se han utilizado categorías gramaticales distintas cuando se ha tratado de explicar el término propuesto por medio de una metonimia9. El hecho de calcar las estructuras formales está en relación con la necesidad de imitar la categoría gramatical de los términos propuestos para su definición y variar solo la forma sémica o conceptual relativa al significado de las palabras o expresiones. De ahí que, interrelacionando con la forma categorial y con la forma conceptual o sémica, se podría establecer una gradación en los mecanismos reformuladores empleados por los informantes para la definición del ítem seleccionado; así, el nivel mínimo de paráfrasis (Alonso Perdiguero, 2014) quedaría reducido a la tautología, donde se establece una similitud plena formal y conceptual, aunque se empleen más elementos para su explicación; el nivel medio estaría en la coincidencia de categoría pero no de forma conceptual, como sucede en la hiperonimiahiponimia; y, por último, el nivel superior de reformulación parafrástica se encontraría en la variación categorial y conceptual, observada en la metonimia (ver gráfico 5 en anexos).

El texto del blog permite contextualizar el término teléfono móvil en el ámbito de la tecnología, pero no presenta información añadida para que pueda ser distinguido con un sentido distinto al habitual en cualquier contexto. De esta manera, se constata la interpretación más cercana al texto, por tautología, en el sema 'teléfono'; a una distancia intermedia le sigue la interpretación por hiperonimia en los semas 'objeto' y 'aparato'; y

A diferencia del ítem teléfono móvil, donde se procede por metonimia, en otros ítems informáticos como nube, se procede por metáfora. Para una mayor información sobre ítems metafóricos puede consultarse Penas Ibáñez y Erlendsdóttir (2014).

SHJ, I (I) (202I) pp. I27-I53. ISSN: 2792-3967 
finalmente, la más alejada del texto, por metonimia, donde se señala la función o la finalidad del aparato, en los semas 'medio' y 'llamar'. El uso de estos últimos semas para definir teléfono móvil no tiene justificación ya que su presencia léxica no aparece en el texto ni tampoco se puede deducir de su contenido. Esta interpretación permite aventurar que la vía metonímica en estos dos semas se ha realizado por el conocimiento del mundo externo que poseen los informantes.

Con respecto a las definiciones lexicográficas y los semas empleados por los informantes, se observa que la hiperonimia y la metonimia son mecanismos semánticos preferentes de reformulación cuando intentan aclarar o explicar el significado de una palabra o expresión (Garcés Gómez, 2008). Cabe destacar en las muestras la frecuente presencia del término que se ha de definir dentro de la definición, hecho coincidente con el de los diccionarios manejados, dado que también incurren en tautología, como se ha comprobado más arriba. Posiblemente, esta esté ocasionada por opción preferida de uno de los miembros elididos en la expresión móvil, ya consagrada en el uso como alternativa de teléfono móvil.

Se concluye, por tanto, de esta aplicación a la comprensión textual de un blog a través de las muestras de los informantes, que un léxico bien estructurado permite explicar muchos fenómenos, no solo de cohesión formal sino de coherencia discursivo-textual y es una buena guía de interpretación para los usuarios.

\section{Referencias}

Alonso Perdiguero, M. (2014): Estudio semántico de la paráfrasis. La paráfrasis como un caso de sinonimia sintagmática. Saarbrücken: Verlag.

Garcés Gómez, M. ${ }^{a}$ P. (2008): La organización del discurso: marcadores de ordenación y reformulación. Madrid/Frankfurt am Main: Iberoamericana/Vervuert.

Moliner, M. (1998): Diccionario de uso del español. Madrid: Gredos.

Penas Ibáñez, M. ${ }^{a}$ A. (2009): Cambio semántico y competencia gramatical. Madrid, Frankfurt am Main: Iberoamericana/Vervuert.

Penas Ibáñez, M. ${ }^{a}$ A. y Alonso Perdiguero, M. (2010): "Procesos inferenciales de semiotización en El Sur de Borges y Erice”, Círculo de Lingüística Aplicada a la Comunicación, 41, 107-143.

Penas Ibáñez, M. ${ }^{a}$ A. y Abad Serna, S. (2011): “Aproximación histórica a la reformulación lingüística de la paráfrasis como un caso de sinonimia sintagmática", Energeia, III, pp. 30-74. Disponible en <http://www.romling.uni- 
tuebingen.de/energeia/zeitschrift/2011/aproximacion-historica-de-la-reformulacionlinguistica.html>.

Penas Ibáñez, M. ${ }^{a}$ A. y Erlendsdóttir, E. (2014): “'́tems léxicos metafóricos de los campos nocionales 'miedo', 'tener hambre' y 'comer mucho' en español, islandés y ruso”, Tonos Digital. Revista de Estudios Filológicos, 26, 1-20.

Penas Ibáñez, M. a A. (2015a): "La traducción intralingüística”, en M. ${ }^{a}$ A. Penas Ibáñez (ed.): La traducción. Nuevos planteamientos teórico-metodológicos. Madrid: Síntesis, 75103.

Penas Ibáñez, M. ${ }^{a}$ A. (2015b): "Significado conceptual y procedimental del léxico informático en el espacio educativo”, Revista Opción, 31, 569-590.

Penas Ibáñez, M. ${ }^{a}$ A. y Alonso Perdiguero, M. (2016): "Generación Millennial y comprensión lectora de ítems informáticos en blogs. El término almacenamiento”, en E. Bernad Monferrer y M. Mut Camacho (eds.): Aula virtual: contenidos y elementos. Madrid / Londres / México / Nueva York / Milán / Toronto: Ediciones Universitarias McGraw-Hill, 423-435.

Penas Ibáñez, M. ${ }^{a}$ A. (2017): "Los semas en la definición del léxico informático. Información semántica y lexicográfica: el término nube”, en B. Almeida Cabrejas et al. (eds.), Investigaciones actuales en Lingüística. Vol. II: Morfología y Lexicología, Alcalá de Henares: Universidad de Alcalá, 243-260.

Penas lbáñez, M. ${ }^{a}$ A. (2018): El cibertexto y el ciberlenguaje. Madrid: Síntesis.

Real Academia Española (2005): Diccionario del Estudiante Secundaria y Bachillerato. Barcelona: Santillana.

Real Academia Española (2014): Diccionario de la lengua española. Madrid: Espasa Calpe, $23^{a}$ edición.

Seco, M., Andrés, O. y Ramos, G. (2016): Diccionario del español actual. Madrid: Aguilar, $2^{\mathrm{a}}$ edición.

SM Diccionario de Secundaria y Bachillerato, disponible en <http://clave.smdiccionarios.com/app.php>.

VOXonline, disponible en <https://www.vox.es/>.

\section{Anexos}




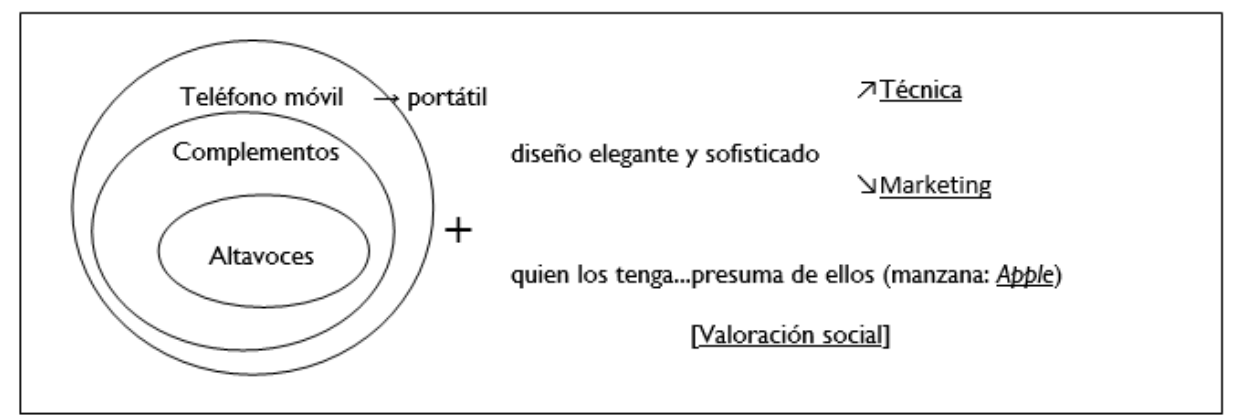

Gráfico I. Fuente: Elaboración propia
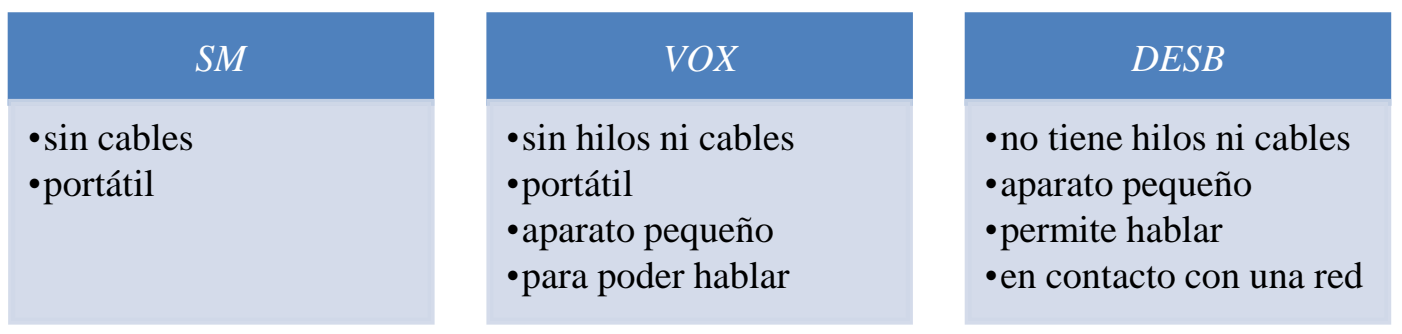

Gráfico 2. Fuente: Elaboración propia
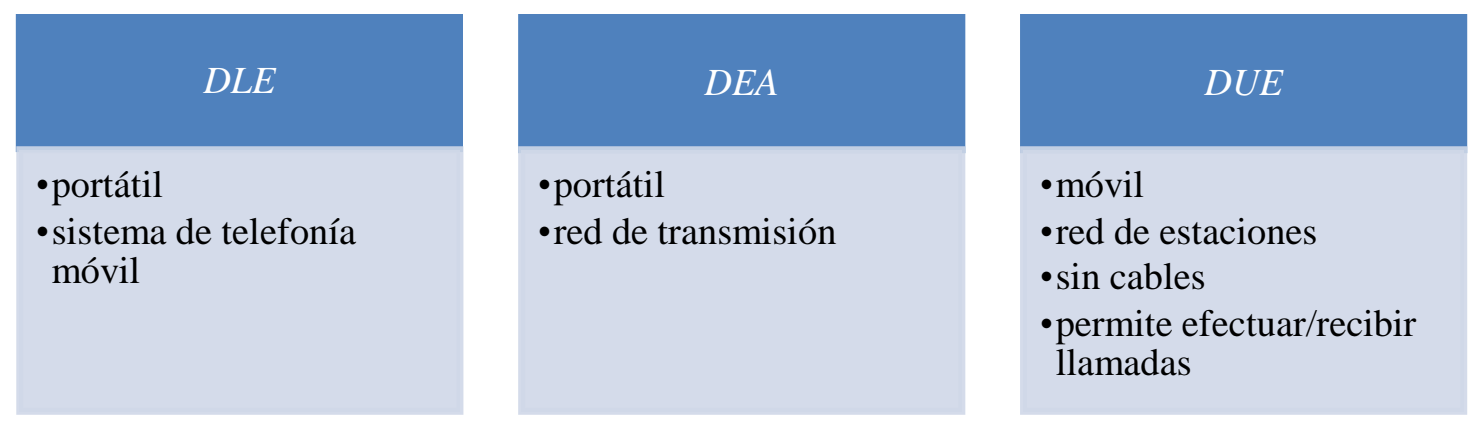

Gráfico 3. Fuente: Elaboración propia 


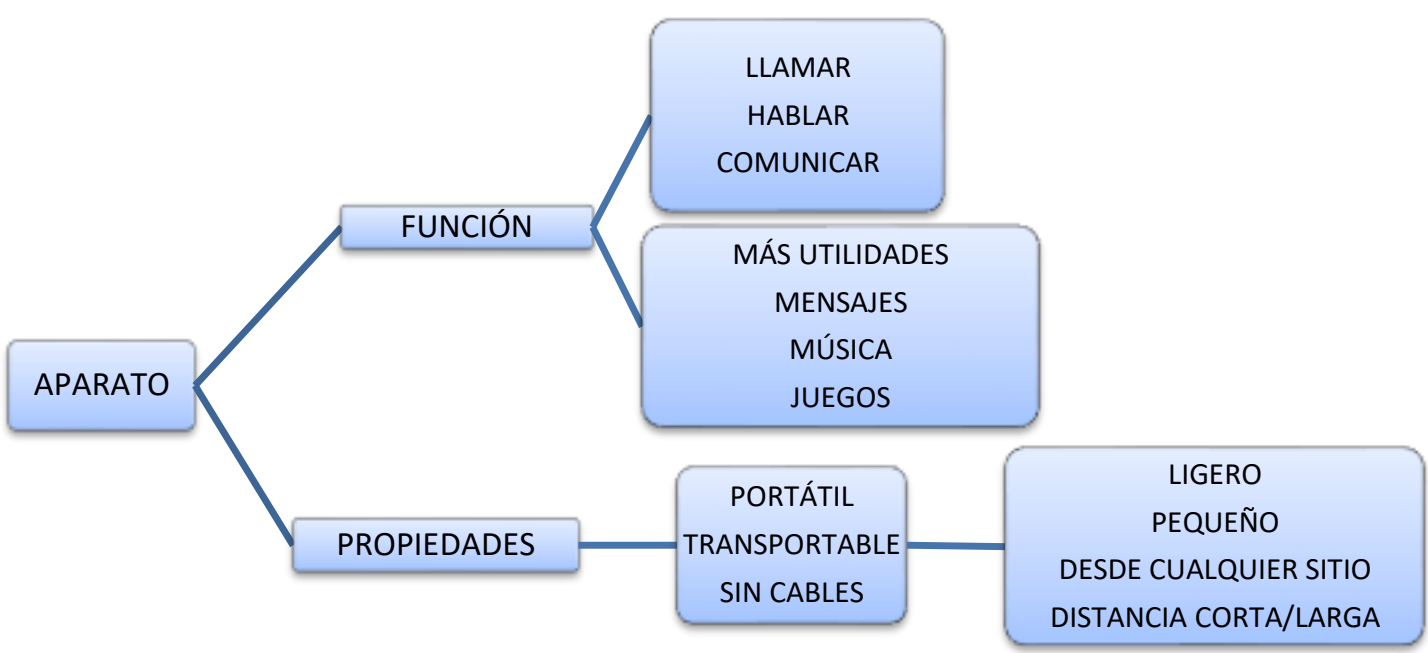

Gráfico 4. Fuente: Elaboración propia
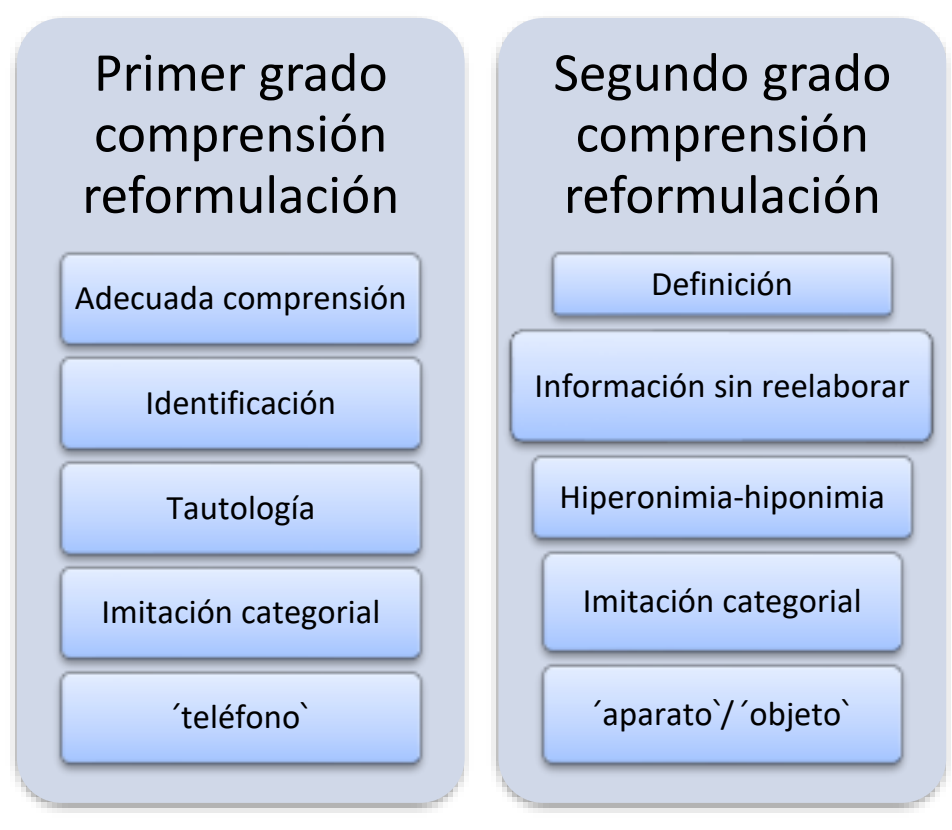

\section{Tercer grado comprensión reformulación}

Relación de elementos

Transformación

Metonimia

Variación categorial

'llamar' /'medio'

Gráfico 5. Fuente: Elaboración propia

\section{Notas biográficas}

M. ${ }^{a}$ Azucena Penas Ibáñez, premio extraordinario de licenciatura, beca FPU en la Universidad de Salamanca, beca postdoctoral Fundación Caja Madrid. Profesora Titular de Lengua española en la UAM. Acreditada al Cuerpo de Catedráticos de Universidad desde 2013. IP del proyecto Semántica y sintaxis de los verbos con doble participio en 
español: herencia latina e indoeuropea en la diátesis y en la voz CAM/UAM Grupos emergentes. Referencia 09/SHD/038. National Coordinator of Spanish Universities and PI of UAM of Project Supporting success for all - Universal Design Principles in Digital Learning for students with disabilities (Success). European Project KA226 - School Education sector in the Erasmus+ Program in 2020. Project number: 2020-1-PL01KA226-SCH-095777. Coordinadora del Grupo de Investigación Semántica LatinoRománica (UAM Grupo F-024 SemLatRom) 2006-2018 y del Grupo de Investigación Semántica y Léxico (UAM F-209 SEMyLÉX 2018-). Miembro investigador del Grupo Léxico de la Universidad de A Coruña (Grupo G000375 GLEX) (2005-) y del Grupo Japón de la Universidad de Zaragoza (Grupo S117 Japón) (2012-). Estancias investigadoras en Lecce, La Sapienza, Reykyavik, Lisboa, Bergen, Coimbra, Cagliari. Dirección de 8 tesis doctorales, con Cum Laude. La última "Estudio semántico contrastivo de la metáfora conceptual en la fraseología del chino y del español" (UAM 2016). Sus principales líneas de investigación son la semántica, el léxico y la lingüística aplicada al discurso, traducción y enacción, con participación en congresos nacionales e internacionales. Entre sus últimas publicaciones cabe citar: "Denominación de las categorías de color básicas. Procesos ontogenéticos y semántico-cognitivos”, Rilce 33.3, 2017; El cibertexto y el ciberlenguaje. Síntesis. 2018; "Cambio semántico y lexemática verbal. De los preverbios latinos a los verbos españoles prefijados y de régimen preposicional. Su relación con los phrasal verbs", Romance Philology 73.1, 2018; “Enacción y léxico: las categorías semánticas de 'el mundo en que vivimos' y 'cómo captamos el mundo' en el sistema de símbolos Bliss”, Lenguaje, paisaje lingüístico y enacción. Tirant Humanidades, 2019; "La preposición en las perífrasis discursivas del español. Un reto para el armenio”, Romanica Olomucensia 32.1, 2020.

Milagros Alonso Perdiguero, doctora en Filología Hispánica por la UAM. Sus principales líneas de investigación son la semántica del discurso. Entre sus publicaciones cabe citar: Estudio semántico de la paráfrasis. La paráfrasis como un caso de sinonimia sintagmática, Saarbrücken: Verlag, 2014; y en colaboración con M. ${ }^{a}$ A. Penas Ibáñez: "Generación Millennial y comprensión lectora de ítems informáticos en blogs. El término almacenamiento", en E. Bernad Monferrer y M. Mut Camacho (eds.): Aula virtual: contenidos y elementos. Madrid / Londres / México / Nueva York / Milán / Toronto: Ediciones Universitarias McGraw-Hill, 423-435, 2016; así como "Procesos inferenciales de semiotización en El Sur de Borges y Erice", Círculo de Lingüística Aplicada a la Comunicación, 41, Pp. 107-143, 2010. Ha participado en congresos internacionales y en seminarios de investigación de la Universidad Autónoma de Madrid. 